\title{
Electrophysiological assessment of visual function in newly- diagnosed IDDM patients
}

\author{
L. Uccioli ${ }^{1}$, V. Parisi ${ }^{2 / 4}$, G. Monticone ${ }^{1}$, L. Parisi ${ }^{3}$, L.Durola ${ }^{1}$, C. Pernini ${ }^{4}$, R. Neuschuler ${ }^{4}$, M. G. Bucci ${ }^{2}$, G. Menzinger ${ }^{1}$ \\ ${ }^{1}$ Cattedra di Endocrinologia, Università di Roma "Tor Vergata", Rome, Italy \\ ${ }^{2}$ Cattedra di Clinica Oculistica, Università di Roma "Tor Vergata", Rome, Italy \\ ${ }^{3}$ II Clinica Neurologica, Università di Roma "La Sapienza", Rome, Italy \\ ${ }^{4}$ Divisione Oculistica Ospedale Fatebenefratelli, Isola Tiberina, Rome, Italy
}

Summary Electrophysiological tests (electroretinogram, oscillatory potentials, visual evoked potentials, in the basal condition and after photostress) reveal an abnormal function of the visual system in insulindependent diabetic (IDDM) patients. The aim of our work was to assess whether electrophysiological abnormalities in visual function exist in newly-diagnosed diabetic patients free of any fluorangiographic signs of retinopathy. Ten control subjects (age $28.7 \pm 2.44$ years) and ten IDDM patients (age $25.2 \pm 6.78$ years; disease duration $5.3 \pm 3.5$ months) in stable metabolic control $\left(\mathrm{HbA}_{1 \mathrm{C}} 7.5 \pm 1.1 \%\right)$ were evaluated. Flash-electroretinograms and oscillatory potentials were similar in both groups. Visual evoked potentials (VEP) recorded under basal conditions showed that P100 latency was significantly increased in the diabetic patients compared to control subjects $(p<0.01)$, while N75-P100 amplitude was similar in both groups. The recovery time of VEP after photostress was equivalent in diabetic patients and control subjects. The impaired basal VEPs suggest an early involvement of the nervous conduction in the optic nerve. However, the preserved flash-electroretinogram and the normal recovery time after photostress indicate that a short disease duration does not induce physiopathological changes in the outer retinal layers or in the macular function. [Diabetologia (1995) 38: 804-808]

Key words Flash electroretinogram, visual evoked potentials, photostress, insulin-dependent diabetes mellitus, diabetic retinopathy, macular function.
In diabetes mellitus visual deficits appear to result from both vascular disease and metabolic abnormalities, which can affect the retina, optic nerve and visual pathways. Electrophysiological methods used to evaluate visual function are the electroretinogram (ERG), which records the electroretinographic signals evoked by flash or pattern stimuli and visual evoked potentials (VEPs), which are the recordings of the cortical potentials evoked by pattern stimuli. In diabetic patients these methods have shown an im-

Received: 8 July 1994 and in revised form: 23 December 1994

Corresponding author: Dr. L. Uccioli, Cattedra di Endocrinologia, c/o Complesso Integrato Columbus, via Pineta Sacchetti 506, I-00168 Roma, Italy

Abbreviations: ERG, Electroretinogram; OPs, oscillatory potentials; VEP, visual evoked potentials; RT, recovery time; FERG, electroretinogram evoked by flash stimuli. paired function of the outer and the inner retinal layers [1-5], of the innermost retinal layers [5-12] and the visual pathways [13-21]. However, to our knowledge, visual function in newly-diagnosed insulin-dependent diabetic (IDDM) patients has not yet been investigated. Therefore, the aim of our study was to assess whether electrophysiological abnormalities in visual function exist in newly-diagnosed diabetic patients.

\section{Subjects and methods}

Ten control subjects (mean age $27.8 \pm 2.44$ years) and ten IDDM patients ( $25.20 \pm 6.78$ years) with a disease duration of less than 1 year $(5.3 \pm 3.5$ months) and with stable metabolic control $\left(\mathrm{HbA}_{1 \mathrm{C}} 7.5 \pm 1.1 \%\right)$ were entered in this study. The following criteria were required for the control subjects: normal intraocular pressure ( $<21 \mathrm{~mm} \mathrm{Hg}$ ), normal visual acuity, normal visual field (Goldmann perimetry) and no ocular or neuro- 
logical problems. The criteria required for diabetic patients were normal intraocular pressure $(<21 \mathrm{~mm} \mathrm{Hg}$ ), best corrected visual acuity 10/10, and absence of retinopathy evaluated by fluoroangiography (Klein level 1) [22]. The patients did not exhibit ketoacidosis or diabetic coma during the 2 months preceding the study and the blood glucose level on the morning of the study was less than $\mathrm{mmol} / \mathrm{l}$.

$E R G$ recording. In all subjects an ERG evoked by flash stimuli (FERG) was recorded using the following method. The subjects under examination were seated in a semi-dark and acoustically isolated room. Prior to the experiment each subject was visually adapted to the background of the flash stimulator (Ganzfeld, see below) for $10 \mathrm{~min}$. The luminosity of the background was about $5 \mathrm{~cd} / \mathrm{m}^{2}$ and the pupil diameter of each subject was about $5 \mathrm{~mm}$. The visual stimulus was Cadwell $7400 \mathrm{Ga}$ nzfeld Stimulator (Pollman, Bologna, Italy) at $1 \mathrm{~J}$ intensity. A single flash was presented at a temporal frequency of $1 \mathrm{~Hz}$. The bioelectrical signal was recorded by means of platinum hook electrodes inserted in the external corner of the inferior eyelid (active electrode). Local anaesthesia was provided by application of novesine $0.4 \%$. A silver/silver chloride electrode was positioned and fixed with collodion in Fpz (International System 10-20 of Electroencephalographic Recording) (reference electrode). The ground electrode was on the left $\mathrm{arm}$. The interelectrode resistance was maintained lower than $10 \mathrm{kOhms}$. The signal was amplified (gain 50000), filtered (band pass $10-200 \mathrm{~Hz}$ ) and averaged (40 events without artifacts were averaged for every trial). The analysis time was $200 \mathrm{~ms}$. The typical FERG is a biphasic signal characterized by a certain number of waves, two of which ( $a$ - and $b$-waves) have mean latencies of 16 and $40 \mathrm{~ms}$ in normal subjects. Furthermore, under our experimental conditions, the first part of the $b$ wave reveals the presence of the oscillatory potentials (OPs). For all FERGs the peak latency and the peak amplitude of each wave (latencies of the a- and b-waves, b-wave amplitude and the amplitude of the OPs) were measured directly on the displayed records of a pair of cursors. The FERG recordings were carried out in the right eye of each subject.

\section{$V E P$ recording}

Basal VEP. The subjects were seated in a semi-dark acoustically isolated room. Prior to the study each subject was adapted to the ambient room light level for $10 \mathrm{~min}$ until their pupil diameter was about $3 \mathrm{~mm}$. The display was surrounded by a uniform field of luminance $5 \mathrm{~cd} / \mathrm{m}^{2}$. VEPs were recorded according to a previously described method $[23,24]$. The visual stimuli were checkerboard patterns (contrast $70 \%$, mean luminance $110 \mathrm{~cd} / \mathrm{m}^{2}$ ) generated on a television monitor and reversed in contrast at a rate of two reversals per second. At a viewing distance of $114 \mathrm{~cm}$ the individual check size subtended $15 \mathrm{~min}$ of visual arc and the screen of the monitor subtended 25 degrees. The stimulation was monocular, after occlusion of the other eye. The test was performed in the right eye of all patients, with occlusion of the left eye.

Cup-shaped silver/silver-chloride electrodes were fixed with collodion in $\mathrm{Oz}$ positions (active electrode), and in Fpz position (reference electrode) with the ground in the left arm. The interelectrode resistance was kept below $3 \mathrm{kOhm}$. The bioelectric signal was amplified (gain 20000), filtered (band-pass 1$100 \mathrm{~Hz}$ ) and averaged, with automatic rejection of the artifacts, over a number of stimulus periods using a Cadwell 7400 .

The recording session began with a preliminary experiment in which at least two VEPs were recorded, averaging over 100 stimulus periods and excluding artifacts. The analysis time was $500 \mathrm{~ms}$.

The transient response was characterized by several waves with three peaks, that in normal subjects appeared after 75100 and $145 \mathrm{~ms}$. These peaks had negative (N75), positive (P100) and negative (N145) polarity, respectively.

$V E P s$ after photostress. After a preliminary trial, a control VEP was recorded, reducing the averages to 40 events per trial (with no more than two sweeps discarded because of artifacts). This VEP record was defined as "basal" and was kept on display on the computer monitor.

Photostress was then induced for $30 \mathrm{~s}$ by means of a circular diffusing surface (the bulb of a 200-W lamp) that was centrally fixated by the subject from a distance of $20 \mathrm{~cm}$ and produced a central scotoma of $6^{\circ}$ diameter. The pupil diameter reduced to about $2 \mathrm{~mm}$.

Immediately after the end of photostress, fixation was shifted to the pattern stimulus and recording of VEPs started. Recordings were taken for successive 20 -s periods (averaging 40 stimuli every $20 \mathrm{~s}$ ) and displayed successively on the monitor until the VEP obtained was superimposable on the basal recording.

The time taken for the VEP to become superimposable was considered as the recovery time after photostress (RT). For all VEPs the peak latency and the peak amplitude for each wave were measured directly from the displayed recordings using a pair of cursors. Our method did not allow us to record in the same averaging run the Pattern-ERG or the Focal-ERG as well as the VEP. A longer time is required to obtain a reliable record from these two ERG recordings than the pre-established recording time allowed by our experimental procedure.

\section{Statistical analysis}

Results are expressed as mean \pm SEM. If not otherwise indicated $n$ refers to the number of eyes. Differences between groups were statistically evaluated with a one-way analysis of variance for repeated measures (ANOVA) and with linear regression and were considered significant with $p<0.05$.

\section{Results}

FERGs in normal subjects and in IDDM patients (Table 1). In control subjects the FERG parameters were within our normal limits [25]. In all IDDM patients the parameters of the FERG were within normal limits and without significant differences from the parameters of the control subjects.

Basal VEPs. The mean data for all groups of patients are shown in Figures 1 and 2 (see basal) and in Table 2 . In control eyes, the VEP parameters (P100 latency and N75-P100 amplitude) were within our normal limits [26] expressed as mean value \pm 1 SD for N75-P100 amplitude $(9.23 \pm 2.18 \mu \mathrm{V})$ and mean value \pm 3 SD for P100 latency $(93.15 \pm 3.43 \mathrm{~ms})$. The mean P100 latency was significantly prolonged in diabetic patients compared to mean value of the control group. N75-P100 amplitude values were similar in both groups. 
Table 1. Flash-ERG parameters in control and IDDM eyes

\begin{tabular}{lllll}
\hline (n) & $\begin{array}{l}\text { Latency } \\
\text { a-wave } \\
(\mathrm{ms})\end{array}$ & $\begin{array}{l}\text { Latency } \\
\text { b-wave } \\
(\mathrm{ms})\end{array}$ & $\begin{array}{l}\text { Amplitude } \\
\text { b-wave }(\mu \mathrm{V})\end{array}$ & $\begin{array}{l}\text { Amplitude } \\
\text { OPs }(\mu \mathrm{V})\end{array}$ \\
\hline $\begin{array}{l}\text { Control } \\
\text { (10) }\end{array}$ & $15.97 \pm 0.4$ & $40.6 \pm 1.2$ & $74.3 \pm 3.2$ & $28.41 \pm 1.05$ \\
$\begin{array}{l}\text { IDDM } \\
(10)\end{array}$ & $15.95 \pm 0.4$ & $40.4 \pm 1.3$ & $74.6 \pm 3.1$ & $27.5 \pm 0.98$ \\
\hline
\end{tabular}

Mean \pm SEM

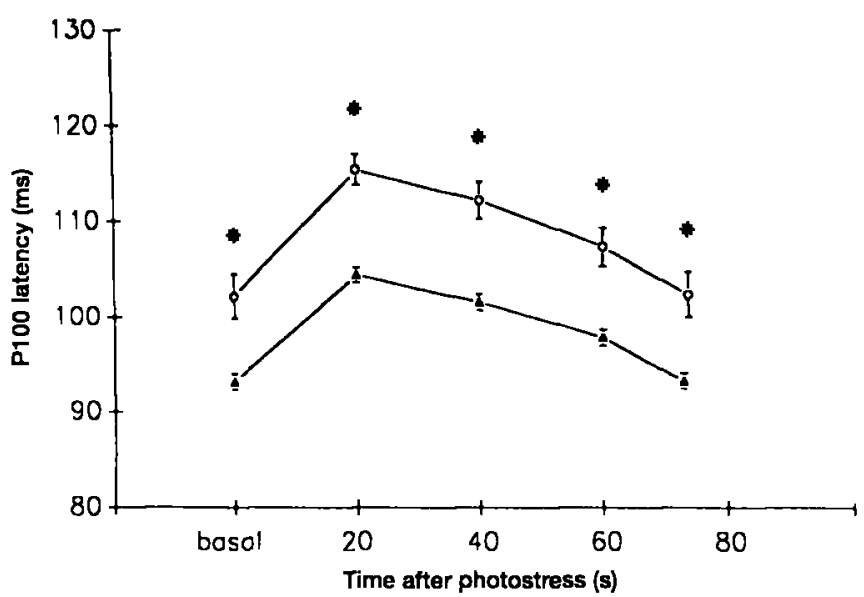

Fig.1. P100 latency under the basal condition and 20, 40,60, 80,100 and $120 \mathrm{~s}$ after photostress in control subjects ( $\longrightarrow$ ( ) and IDDM patients with less than 1 year disease duration $(0 \multimap) ;{ }^{*} p<0.01$. Mean \pm SEM

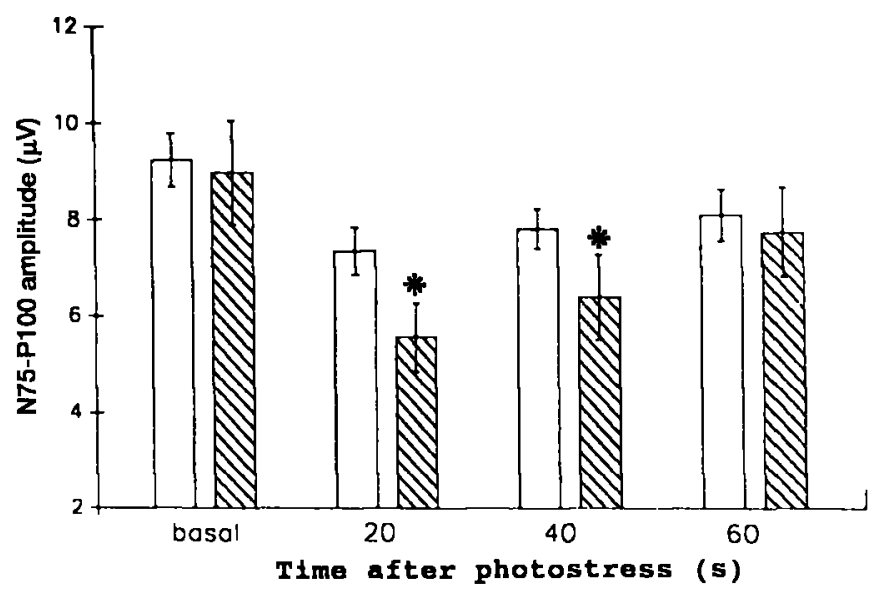

Fig.2. VEP amplitude under basal conditions and 20, 40 ancl 60 s after photostress in control subjects ( $\square$ ) and IDDM pati.ents $(\mathbb{N})$ with less than 1 year disease duration; ${ }^{*} p<0.01$. Mean \pm SEM

$V E P s$ after photostress: control eyes. The mean results; of P100 latency and N75-P100 amplitude are presented in Tables 2 and 3 . Figures 1 and 2 show P10() latency and N75-P100 amplitude after photostress. At $20 \mathrm{~s}$ after photostress we observed an increase in P100 latency and a decrease in N75-P100 amplitude. At 40 and $60 \mathrm{~s}$ after photostress the P100 latenciess were shorter in duration than the 20 -s value, but still longer than in the basal P100 latency. The N75-P100 amplitude increased from the value observed at $20 \mathrm{~s}$, but without reaching the basal value. Examples from one normal subject (V.P.) are shown in Figure 3. The RT was $73.0 \pm 2.21 \mathrm{~s}$.

$V E P s$ after photostress in IDDM patients. Figures 1 and 2 show that in IDDM patients the response to photostress followed a similar pattern to that described for control subjects. The mean percentage decrements of N75-P100 amplitude observed at 20, 40 and $60 \mathrm{~s}$ after photostress were significantly higher in diabetic eyes than in control eyes $(p<0.01)$ (Table 3 ). The mean increments in P100 latency observed at 20, 40 and $60 \mathrm{~s}$ after photostress and the RT were similar in both groups (Tables 2 and 3). Examples from one diabetic subject (S. A.) are shown in Figure 3.

\section{Discussion}

Flash-ERG has been utilized to assess the bioelectrical activity of the outer retinal layers, and the OPs to evaluate the activity of the inner retinal layers [27]. Some authors have revealed abnormalities of FERG and in particular of OPs in IDDM patients [1-5].

In our experience FERG and OP parameters did not differ between control subjects and newly-diagnosed IDDM patients. Our data suggest that in early IDDM the outer and the inner retinal layers are not functionally impaired. The discrepancy with other authors may be explained by the disease duration of our subjects being less than 1 year. In addition, other studies have included patients with background retinopathy [2,4], while our patients were free of any clinical or fluoroangiographic sign of retinopathy.

Several studies have assessed the visual pathway function by VEP recordings and observed a delay in latency in patients with long-standing diabetes [1321]. This has been ascribed to a reduced velocity of nervous conduction in the optic nerve, as further supported by studies with the Pattern-ERG [6-12], and with the measuring of the retino-cortical time [11, 20]. In the newly-diagnosed IDDM patients we found an impaired P100 latency in the basal VEP compared to control subjects. As macular activity contributes to the VEP an objective way of evaluating macular function is to record VEP after photostress [28-30]. The changes induced by photostress on the VEP can be attributed to a reduced activity of the outer and/or innermost retinal layers of the macula after dazzling [23, 24].

In our newly-diagnosed IDDM patients the mean increment of the P100 latency and the RT values after photostress were similar to those in control subjects. The high intra-subject variability observed in the N75-P100 amplitude recordings made under ba- 
Table 2. VEP P100 latency values under basal conditions and 20,40 and $60 \mathrm{~s}$ after photostress in control and IDDM eyes

\begin{tabular}{llllc}
\hline$(n)$ & P100 Latency basal $(\mathrm{ms})$ & $20 \mathrm{~s}(\mathrm{~ms})$ & $40 \mathrm{~s}(\mathrm{~ms})$ & $60 \mathrm{~s}(\mathrm{~ms})$ \\
\hline Control (10) & $93.1 \pm 3.36$ & $104.06 \pm 2.48$ & $101.56 \pm 2.1$ & $98.37 \pm 1.83$ \\
IDDM (10) & $102.01 \pm 5.84^{\mathrm{a}}$ & $115.16 \pm 3.99^{\mathrm{a}}$ & $111.96 \pm 4.8^{\mathrm{a}}$ & $107.14 \pm 5.01^{\mathrm{a}}$ \\
\hline
\end{tabular}

a $p<0.01$

Mean \pm SEM

Table 3. VEP N75-P100 amplitude mean \% decrement, P100 latency increment and recovery time after photostress in control subjects and IDDM patients

\begin{tabular}{llll}
\hline & $\begin{array}{l}\text { N75-P100 } \\
\text { amplitude } \\
\text { mean \% } \\
\text { decrement }\end{array}$ & $\begin{array}{l}\text { P100 latency } \\
\text { mean incre- } \\
\text { ment }(\mathrm{ms})\end{array}$ & $\begin{array}{l}\text { Recovery time } \\
(\mathrm{s})\end{array}$ \\
\hline Control & $\begin{array}{l}14.08 \pm 1.25 \\
\text { IDDM }\end{array}$ & $9.1 \pm 0.92$ & $73.0 \pm 0.61$ \\
\hline
\end{tabular}

${ }^{a} p<0.01$

Mean \pm SEM
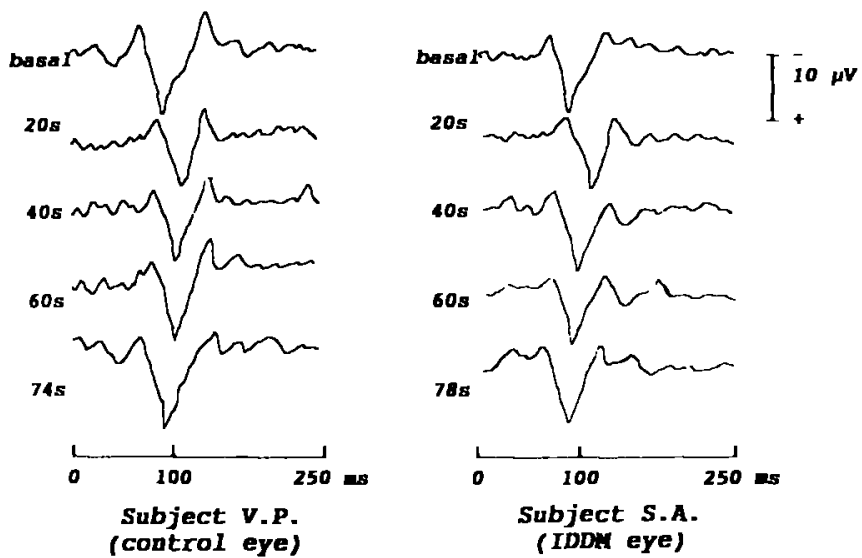

Fig. 3. VEP recording of subjects V.P. (control eye) and S. A. (IDDM eye) under normal conditions (basal) and 20, 40 and $60 \mathrm{~s}$ after photostress. VEPs recorded in the IDDM eye at 20 , 40 and $60 \mathrm{~s}$ after photostress show a longer P100 latency and a reduced amplitude compared to control. The VEPs are superimposable on the basal waveform at $74 \mathrm{~s}$ in the control eye, and at $78 \mathrm{~s}$ in the IDDM eye

sal conditions and after photostress leads us to consider this parameter not sufficiently reliable for interpretation. On the contrary, the increment in P100 latency and the RT are highly reliable parameters $[19$, 31]; therefore, since they were similar in the control subjects, we conclude that a very short disease duration (5.3 \pm 3.5 months) does not induce pathological changes in macular function.

Using another method to explore macular function (focal-ERG) Ghirlanda et al. [32] observed selective neurosensory deficits in the inner retinal layers in IDDM patients with short duration of disease $(3.8 \pm 3.5$ years). Our data might appear to be in contrast but the shorter disease duration of our patients could provide an explanation. Furthermore, in our previous study [33] we found an impaired macular function in diabetic patients without retinopathy but with a disease duration of $11.5 \pm 5.2$ years. In conclusion, the impaired basal VEPs suggest an early involvement of the nervous conduction in the optic nerve. However, the preserved FERG and the normal RT after photostress indicate that a short disease duration does not induce physiopathological changes in the outer retinal layers or in the macular function. The delayed conduction along the optic pathways during the early phases of diabetes seems to be a functional phenomenon, as reported for peripheral nerves [34], rather than a consequence of pathological changes of the optic nerve fibers. In fact a recent report [35] has shown that short-term strict metabolic control is able to improve VEP latencies in patients with poorly-controlled diabetes. Our study also suggested that metabolic control plays a role in the pathogenesis of VEP alterations by showing that our patients, although in stable metabolic control, were in unsatisfactory glycaemic control with an $\mathrm{HbA}_{1 \mathrm{c}}$ of $7.5 \pm 1.1 \%$.

\section{References}

1. Bresnik GH, Palta M (1987) Temporal aspects of the electroretinogram in diabetic retinopathy. Arch Ophthalmol 105: 660-664

2. Gjotteberg M (1974) The electroretinogram in diabetic retinopathy. A clinical study and critical survey. Acta Ophthalmol 52: 521-533

3. Simonsen SE (1975) Prognostic value of ERG (oscillatory potentials) in juvenile diabetics. Acta Ophthalmol 123 [Suppl]: 223-224

4. Van Der Torren K, Van Lith G (1989) Oscillatory potentials in early diabetic retinopathy. Doc Ophthalmol 71 : 375-379

5. Coupland SG (1987) A comparison of oscillatory potential and pattern electroretinogram measures in diabetic retinopathy. Doc Ophthalmol 66: 207-218

6. Arden GB, Hamilton AMP, Wilson-Holt J, Ryan S, Yudkin JS, Kurtz A (1986) Pattern electroretinograms become abnormal in the preproliferative stage: possible use as a screening test. Br J Ophthalmol 70: 330-335

7. Boschi MC, Frosini R, Menicucci R, Sodi A (1989) The influence of early diabetes on pattern electroretinogram. Doc Ophthalmol 71: 369-374

8. Falsini B, Porciatti V, Scalia G et al. (1989) Steady-state electroretinogram in insulin-dependent diabetics with no or minimal retinopathy. Doc Ophthalmol 73: 193-200

9. Martinelli V, Merenda M, Natali-Sora MG, Meschi F, Beccaria L, Comi G (1987) Correlation between pattern electroretinography and visual evoked potentials in diabetes. Electroenceph Clin Neurophysiol 66: S64

10. Porciatti V, von Berger GP (1983) Pattern electroretinogram and visual evoked potentials in optic nerve disease: 
early diagnosis and prognosis. Doc Ophthalmol Proc Ser 40: $117-126$

11. Trick GL, Burde RM, Gordon MO, Kilo C, Santiago JV (1988) Retinocortical conduction time in diabetics with abnormal pattern reversal electroretinogram and visual evoked potentials. Doc Ophthalmol 70: 19-28

12. Martinelli V, Filippi M, Meschi F, Pozza G, Canal N, Comi GC (1991) Electrophysiological study of optic pathways in insulin dependent diabetes mellitus. Clin Vision Sci 6: $437-443$

13. Pozzessere G, Rizzo PA, Valle E et al. (1989) A longitudinal study of multimodal evoked potentials in diabetes mellitus. Diabetes Res 10: 17-20

14. Algan M, Ziegler O, Gehin P et al. (1989) Visual evoked potentials in diabetic patients. Diabetes Care 12: 227-229

15. Cirillo D, Gonfiantini E, De Grandis D, Bongiovanni L, Robert JJ, Pinelli L (1984) Visual evoked potentials in diabetic children and adolescents. Diabetes Care 7: 273-275

16. Collier A, Mitchell JD (1985) Visual evoked potentials and contrast sensitivity function in diabetic retinopathy. BMJ 291: 248

17. Comi G, Martinelli V, Galardi G et al. (1986) Visual evoked potentials in diabetic teenagers: influence of metabolic control and relationship with peripheral neuropathy. Meth Pediat Systems Ophthal 9: 85-87

18. Comi G, Martinelli V, Galardi G et al. (1987) Evaluation of central nervous conduction by visual evoked potentials in insulin-dependent diabetic children. Metabolic and clinical correlation. Acta Diabetol Lat 24: 157-162

19. Puvanendran K, Davethasan G, Wong PK (1983) Visual evoked responses in diabetes. J Neurol Neurosurg Psychiat 46: 643-647

20. Sartucci F, Tognoni G, Guerrini V (1993) Combined use of pattern electroretinograms and visual evoked potentials in evaluation of early visual system involvement in type I diabetic children and adolescents. It $\mathrm{J}$ Clin Neurophysiol 2: 10-24

21. Uccioli L, Monticone G, Parisi V, Parisi L, Bucci MG, Menzinger G (1993) Potenziali evocati visivi in soggetti diabetici insulino-dipendenti con e senza retinopatia. Giorn Ital Diab 13 (3): 259-264

22. Klein BEK, Davis MD, Segal P (1984) Diabetic retinopathy: assessment of severity and progression. Ophthalmology 91: 10-17

23. Parisi V, Bucci MG (1992) Visual evoked potentials after photostress in patients with primary open-angle glaucoma and ocular hypertension. Invest Ophthalmol Vis Sci 33: $436-442$
24. Bucci MG, Parisi V, Giannini R, Rossini PM (1991) Recordings of visual evoked potentials after photostress in artificially increased intraocular pressure. Clin Vision Sci 6: 431-436

25. Parisi V, Uccioli L, Monticone G et al. (1993) Registrazione dei potenziali evocati visivi e dei potenziali oscillatori dell' elettroretinogramma fotopico in pazienti diabetici insulino-dipendenti con e senza retinopatia. Giornale di Medicina Militare 6: 664-671

26. Rizzo P, Carboni M, Passaro R et al. (1988) Potenziali evocati visivi da checkerboard pattern reversal: dati normativi. Riv Med Aeronautica e Spaziale 2: 99-105

27. Armington JC (1974) The electroretinogram. Academic Press, New York

28. Lovasik JV (1983) An electrophysiological investigation of the macular photostress test. Invest Ophthalmol Vis Sci 24: $437-441$

29. Franchi A, Magni R, Lodigiani R, Cordella M (1987) VEP pattern after photostress: an index of macular function. Graefe's Archive Clin Exp Ophthalmol 225: 291-294

30. Bianchini E, Franchi A, Manni R, Villani LG, Cordella M, Botta GC (1987) Carotid occlusive disease: an electrophysiological macular investigation. J Cardiovasc Surg 28: 524 527

31. Halliday AM (1978) Clinical application of evoked potentials. In: Matthews WB, Glaser GH (eds) Recent advances in clinical neurology. Churchill Livingstone, Edinburgh p. 52

32. Ghirlanda G, Di Leo MAS, Caputo S et al. (1991) Detection of inner retina dysfunction by steady-state focal electroretinogram pattern and flicker in early IDDM. Diabetes 9: 1122-1127

33. Parisi V, Uccioli L, Monticone G, Parisi L, Menzinger G, Bucci MG (1994) Visual evoked potentials after photostress in insulin-dependent diabetic patients with or without retinopathy. Graefe's Arch Clin Exp Ophthalmol 232: 193-198

34. Gallai V, Agostini L, Rossi A et al. (1978) Evaluation of the motor and sensory conduction velocity in diabetic patients before and after a three-day treatment with the artificial beta cell (Biostator). In: Canal N, Pozza G (eds) Peripheral neuropathies. Elsevier Amsterdam, pp 287-289

35. Ziegler O, Guerci B, Algan M et al. (1994) Improved visual evoked potential latencies in poorly controlled diabetic patients after short-term strict metabolic control. Diabetes Care 17: 1141-1147 